\title{
SUBJETIVIDADES
}

\section{Relatos de Experiências}

\section{FRAGMENTOS DAS ANÁLISES DE DOIS CASOS DE ESQUIZOFRENIA}

\section{Fragments of Two Cases of Schizophrenia Analysis}

\section{Fragmentos de los Análisis de dos Casos de Esquizofrenia}

\section{Fragments de L'analyse de deux Cas de Schizophrénie}

DOI: $10.5020 / 23590777.16 .2 .132-141$

\section{Marisa Terezinha Garcia de Oliveira (Lattes)}

Especialista em Atendimento Clínico com ênfase em Psicanálise pela UFRGS. Membro da Associação Psicanalítica de Porto Alegre (APPOA).

\section{Liliane Seide Froemming (Lattes)}

Doutora em Psicologia do Desenvolvimento pela UFRGS. Professora do Instituto de Psicologia da UFRGS. Psicanalista Membro da Associação Psicanalítica de Porto Alegre (APPOA).

\section{Resumo}

O presente texto foi construído a partir de fragmentos das análises de duas pacientes. A primeira apresentou-se como esquizofrênica na sessão inicial. A segunda foi diagnosticada ao longo do tratamento. Aspectos transferenciais em ambos os tratamentos impulsionaram esta escrita que partiu do texto de Freud sobre "O Caso Dora" e se utilizou da linguagem cinematográfica, pela semelhança entre a montagem de um filme e sessões de psicanálise. O enunciado da primeira sessão de ambas as mulheres e seus sonhos são os fragmentos que nos fizeram recorrer ao estudo de Freud "Suplemento metapsicológico à teoria dos Sonhos" visando análise, interpretação e considerações sobre a estruturação psicótica.

Palavras-chave: psicanálise; esquizofrenia; sonhos; transferência; cinema.

\section{Abstract}

The present text was constructed from fragments of two patients' analysis. The first presented as schizophrenic in the initial session The second was diagnosed throughout the treatment. Transferential aspects in both treatments stimulated this writing that started from Freud's text on "The Dora Case" and used the cinematographic language, for the similarity between the assembly of a film and sessions of psychoanalysis. The statement of the first session of both women and their dreams are the fragments that have made us resort to Freud's study "Metapsychological Supplement to Dream Theory" aiming analysis, interpretation and considerations on psychotic structuring.

Keywords: psychoanalysis; schizophrenia; dreams; transfer; movies.

\section{Resumen}

Este texto fue construido partiendo de fragmentos de los análisis de dos pacientes. La primera se presentó como esquizofrenia en la sesión inicial. La segunda fue diagnosticada a lo largo del tratamiento. Aspectos transferenciales en ambos los tratamientos impulsaron este trabajo basado en el texto Freud acerca del "Caso Dora" y se utilizó del lenguaje cinematográfico, por la semejanza entre el montaje de una película y sesiones de psicoanálisis. El enunciado de la primera sesión de ambas las mujeres y sus sueños son los fragmentos que nos hicieron recurrir al estudio de Freud "Suplemento metapsicológico de la teoría de los sueños" teniendo en vista el análisis, la interpretación y las consideraciones acerca de la estructura psicótica.

Palabras clave: psico-análisis; esquizofrenia; sueños; transferencia; cinema. 


\section{Résumé}

Ce texte a été construit à partir de fragments des analyses de deux patientes. La première patiente s'est présentee comme schizophrène dans la session initiale. La seconde a été diagnostiquée pendant le traitement. Les aspects transferéntiels dans les deux traitements ont stimulé cette écrituret qui a eu comme point de départ le texte de Freud sur «l'affaire Dora» et a utilisé le langage cinématographique grâce à la similitude entre le montage d'un film et les sessions de psychanalyse. Le libellé de la première session des deux femmes et leurs rêves sont les fragments qui nous ont fait tourner vers l'étude de Freud «complément métapsychologique à la science des rêves» dont le cible est analyser, interpréter et donner des considérations sur la structuration psychotiques.

Mots-clés: psychanalyse; schizophrénie; rêves; transfert; cinéma.

O saber é posto no centro da experiência psicanalítica: o saber que não se sabe, o saber inconsciente e a fantasia sobre o saber fechado, total, completo. É a partir de um fragmento e não da totalidade da análise de um caso de histeria e apoiado em dois sonhos, que Freud (1901/1989, p.114) demonstra como um "erro técnico" impulsionou-o à escrita do texto exemplar sobre a transferência, conceito fundamental na psicanálise. Trata-se de "Fragmento da Análise de um Caso de Histeria" cujo primeiro título foi Traum und Hysterie,(Sonhos e histeria) em 1901, também conhecido como "O caso Dora". Ainda, foi a partir deste fragmento que Lacan (1998a) escreveu "Intervenção sobre a transferência", mostrando a experiência dialética que foi a análise de Dora e o quanto Freud vibra, nesta análise, com a "vitória do amor" (Lacan, 1998a, p. 223) mesmo após o malogro do tratamento, comparando o caso ao da "Princesa de Clèves" (Lafayette, 2013). Neste, considerado o primeiro romance psicológico da história da literatura, a princesa desenvolve um intenso debate interior com as suas próprias emoções, dividida entre o marido, Príncipe de Clèves e o Duque de Nemours, sendo o triângulo amoroso evidente e intenso.

Seguindo o caminho de Freud pelo fragmento de análise, pelo erro e também pelos sonhos, resolvemos construir o presente texto para concretizar experiências de escuta psicanalítica que produziram efeitos difíceis de relatar e que, por outro lado, nos impedem de calar e de esquecer, exigindo uma transmissão sem muita inteligibilidade segundo o conceito de "sem expressão" em Walter Benjamin, discutido por Gagnebin (2007, p. 102). O "sem expressão" é o indício da verdade que rompe com a narrativa coerente da história ordinária num ponto onde pode surgir outra história ou outra verdade, como um corte na cadeia associativa do analisante ou mesmo, como a delimitação de uma cena para a montagem de um filme. Fazemos esta comparação recorrendo ao texto de Froemming (2000) "Era como num sonho... Era como num filme" que aproxima a montagem de cenas para a produção de um filme e a associação livre de ideias em sessões de análise.

Assim como o roteiro de Freud ao escrever o caso Dora estrutura-se como narrativa/ montagem a partir de dois sonhos, nosso roteiro contempla fragmentos da análise, sonhos e desfechos provavelmente decorrentes da impossibilidade de trabalhar a transferência.

Nele, começamos pelo fim, num flashback, utilizando a linguagem cinematográfica, que contextualiza o tema e impulsiona a escrita.

- Término do tratamento e seus efeitos no analista.

- Primeiro enunciado.

- Relato de sonho.

- Análise e interpretação do sonho.

- Peculiaridades da transferência e do fim do tratamento.

\section{Término dos Tratamentos e seus Efeitos no Analista}

Trata-se de duas pacientes que aqui designaremos pelos nomes fictícios de Lisa e Maria, segundo adequação ética para publicação discutida por Goldim e Fleck (2010), cujos tratamentos começaram com a defasagem de seis meses. O término de ambos provocou dúvida e perplexidade, um efeito de suspensão, no caso de Lisa e de corte, pela internação de Maria. Pensamos, inicialmente, em escrever unicamente sobre o tratamento de Lisa, mas, depois, nos pareceu que fazer um estudo dos dois casos, contribuiria mais para tramar as falas que escutamos.

Lisa, após insistir fortemente no pagamento adiantado de uma sessão, ausentou-se por duas semanas dos atendimentos. Posteriormente a um contato telefônico, respondeu que estava bem, mas que não viria mais à Instituição. Havia entrado em acordo com sua família em não mais retornar, agradecendo atenção a ela dispensada. 
Maria, em sua última sessão, falou de um novo estágio que começaria na próxima semana. Queixou-se de que no ano anterior tinha sido abandonada por todos, pela mãe, pelo professor/orientador e pela própria terapeuta. Apontamos que o tratamento, ainda não havia começado, naquela época, e que, portanto, não podíamos ter abandonado uma paciente que ainda nem conhecíamos. Confrontamos Maria com realidade. Porém, a posteriori, ao escrever este texto, percebemos que a cronologia dos fatos não se impunha a Maria que esteve sempre usando uma linguagem do inconsciente permeada pela "ausência de contradição, atemporalidade e substituição da realidade externa pela realidade psíquica" (Freud, 1915/2006a, p.38).

$\mathrm{Na}$ fala de Lisa surgiu uma alusão as duas instituições, a família e a Clínica; um acordo com a primeira e uma desistência da segunda. No caso de Maria apareceu a palavra abandono, do qual ela foi vítima.

Segundo Froemming (2000, p.37) "tanto na fala de um paciente em análise quanto na produção de um filme, algo da ordem de uma cadeia associativa se produz" e também cortes nesta cadeia podem ser identificados. Verificamos, agora, que a afirmação de Maria de ter sido abandonada, foi uma indicação do que aconteceria, numa tentativa de repetir ativamente o que sofreu passivamente, o abandono. Supomos na fala destas pacientes uma lógica, que nos conduziria aos efeitos ocorridos, apontando as palavras: família e Clínica, no caso de Lisa, que designam duas instituições e a desistência de uma delas. Para Maria, apontamos a palavra abandono. Na nossa interpretação estas palavras decorrem de uma sobredeterminação que permeia os casos e que se impôs aos tratamentos.

\section{O Enunciado da Primeira Sessão}

Ao nos determos nos enunciados da primeira sessão e à aproximação entre fala da paciente e a composição de um filme, estamos fazendo uma leitura baseada num close, ampliando as vinhetas dos casos no espaço do texto, como se ampliássemos a imagem de um filme no eixo do espaço.

— Sou esquizofrênica paranoide, apresentou-se Lisa, reproduzindo o diagnóstico médico como identificação.

- Fui estuprada aos dois anos e meio por dois vizinhos, mas não quero falar sobre isso; disse Maria.

Os sofrimentos escutados, não resolvidos e advindos da experiência pessoal, repetem-se como garantia de identidade do sujeito, mas, ao mesmo tempo, o aprisionam. A quebra da coerência ilusória destas histórias por outra interpretação viria a acirrar uma luta entre duas versões de uma vida como discute Gagnebin (2007, p. 107).

Temos aqui, questões sobre os tratamentos e sobre a escrita destes casos.

Como intervir? Fazendo um confronto com a realidade e questionando o delírio ou desdobrando as apresentações entre identidade e sofrimento? Como testemunhar para manter as palavras, as histórias destes sujeitos? Como manter seu anonimato, sem deixar de lado tudo o que disseram?

Ainda Gagnebin (2009, p.50), a partir de conceitos emprestados à filosofia de Walter Benjamin, trata de temas como experiência e narração, não com fim moralizante, ou quanto ao conteúdo da mensagem, mas visando a transmissibilidade. Esta é uma dimensão que nos transcende e que cada um de nós porta, evitando a perda da experiência, em especial aquelas que ferem, cortam ao sujeito o acesso ao simbólico, à linguagem, como a experiência do choque e do trauma. Trata-se, então, de transmitir o real, a dimensão psíquica que Lacan (1998b, pp. 77-95) introduziu para designar a realidade própria da psicose (delírio, alucinação) na medida em que é composta de significantes rejeitados do simbólico (Roudinesco \& Plon, 1998, p. 645). "Esta ideia de retorno no real tem como modelo o conceito de retorno do recalcado, empregado por Freud para explicar" a neurose (D'Agord, 2005, p.6).

Lisa identifica-se com sua doença, esquizofrenia-paranoide; ela é seu próprio sofrimento, desdobrado em esquizofrenia e paranoia. O desdobramento que aparece no início do tratamento de Lisa, também aparece nos principais temas da sua fala: a dúvida sobre quem é seu pai, B ou I; sua bissexualidade contada nas histórias de seus namorados e namoradas e as duas instituições citadas, a família e a Clínica, ao desistir do tratamento. A família é a fonte dos conflitos quanto à filiação e sexuação e a Clínica é a instituição que participa da sua vida desde seu primeiro surto.

Maria relata um fato monstruoso que lhe ocorreu aos dois anos e meio, mas se nega a falar sobre isso, embora seja seu primeiro enunciado, o que a identifica e o que é falado ao longo de todo o tratamento. Duas afirmações se desdobram: o estupro inicial, seguido por afirmações que é pura e inocente. Situações persecutórias são relatadas. Os perseguidores são homens com os quais ela tem amores platônicos, mas também a perseguem, estupram e a assediam moralmente. Por outro lado, afirma em muitas sessões ser pura e sem filtro. O contraste entre sua pureza afirmada em muitas sessões e a situação de ter sido vítima de estupros e assédios remete à dialética entre o profano e o sagrado, discutido por Agamben (2007, p.65) ao tratar do objeto, onde "profano" é o que é devolvido ao uso e propriedade dos homens. Os episódios persecutórios quando colegas entram em seu apartamento pela televisão e pelo computador apontam para alucinação, em que o dentro e o fora não estão definidos. 
O problema da alucinação é tratado na obra de Freud, no trabalho de 1917, "Suplemento Metapsicológico a Teoria dos Sonhos", numa discussão de como distinguir fantasia de realidade e também sobre os efeitos do sono nos diferentes sistemas psíquicos.

No "Suplemento", o sonho é descrito como uma projeção, um mecanismo de defesa contra uma interrupção que pode vir de uma excitação interna ou externa. Para se preservar, o narcisismo do sono retira catexias de todas as ideias de objetos das parcelas tanto inconscientes quanto pré-conscientes destas ideias. Catexia (investimento) refere-se ao movimento de alocar energia na direção de representações ligadas ao mundo externo ou às percepções internas (Hanns, 1996). Assim, dentro dos domínios do ego, todos os sistemas ficam esvaziados de catexias. Alguns pensamentos pré-conscientes podem reter parte de suas catexias e estabelecer conexão com material inconsciente depois do inicio do sono, graças à permeabilidade entre os dois sistemas. Forma-se o desejo onírico pré-consciente que dá expressão ao impulso inconsciente no material dos resíduos pré-conscientes do dia. O impulso carregado de desejo pode seguir três caminhos:

1 - Exercer pressão do pré-consciente para a consciência, transformando-se numa ideia delirante, tendo como conteúdo a satisfação do desejo, mas não acontece no estado de sono.

2 - Desviar-se do consciente achando uma descarga motora direta, sob a forma de sonambulismo.

3 - Seguir um curso regressivo até a percepção que exerce pressão sobre a consciência.

Esta regressão é tópica, de lugares: do Pré-consciente através do Inconsciente até a Percepção. É o retorno à etapa inicial da satisfação do desejo da alucinação. Os pensamentos se transpõem em imagens, predominantemente visuais e as representações de palavras são levadas de volta a representações de coisas que lhes correspondem, o que Freud (1915/2006a) designa de processo psíquico primário. Existe livre comunicação entre catexia de palavra e catexia de coisa, dos pensamentos latentes aos elementos oníricos que são percepções sensoriais. O desejo onírico é alucinado e, enquanto alucinação encontrase com a crença da realidade de sua satisfação.

A formação de fantasia carregada de desejo e sua regressão à alucinação não ocorre somente nos sonhos. Segundo Allouch (2004, p. 84) Freud forja o termo PAD (Psicose Alucinatória do Desejo), objeto evanescente que subsume a amentia de Meynert, a fase alucinatória da esquizofrenia e o sonho e vê na amentia "um belo sonho diurno" (Allouch, 2004, p. 90), uma psicose alucinatória transitória. A descrição desta patologia por Meynert, forneceu a Freud a intuição do mecanismo da realização de desejo (Allouch, 2004, p. 81). A alucinação traz consigo a ideia de realidade e a relação com o mundo externo depende de nossa capacidade de distinguir percepção de ideias. No começo da vida mental alucinamos o objeto que nos satisfaria, mas a falha na satisfação almejada nos permite distinguir percepções carregadas de desejo de uma real satisfação, estabelecendo uma prova de realidade. Ela está entre as principais instituições do ego, embora na amentia de Meynert, o ego rompa sua relação com a realidade, com a percepção, que é considerada coincidente com o consciente. Já nos sonhos, esta retirada de catexia do consciente e dos outros sistemas psíquicos (Pcs e Ics) visa à preservação do sono.

Num determinado momento da teorização de Freud (1900-01/1996, p. 558) quanto à interpretação dos sonhos, ele diz que "nosso procedimento consiste em focalizar nossa atenção num único elemento do sonho e então tomar nota de todos os pensamentos involuntários que possam ocorrer-nos a propósito dele", pois, "é notável quão pouco a elaboração do sonho obedece às representações da palavra: ela está sempre pronta a trocar uma palavra por outra até encontrar a expressão mais conveniente para representação plástica" (Freud, 1917/1999, pp. 80-81). Aqui, aparece a referência aos fatores envolvidos na formação do conteúdo dos sonhos: a condensação, o deslocamento e a escolha de imagens (representabilidade).

Já nos sonhos diurnos e na amentia de Meynert, segundo Allouch (2004, p.91) há uma ausência do trabalho e, portanto, a realização de desejo é imediatamente visível.

Voltando às falas de Lisa e Maria, escolhidas para ilustrar seus sofrimentos, apontamos que, como foram endereçadas ao analista, a escolha destas falas para compor este texto, também é atravessada pela transferência. Assim, há uma liberdade relativa nesta escolha, na medida em que os elementos e suas sequências para ilustrar os casos clínicos, seguem traços fundamentais, como a organicidade e o pathos (Froemming, 2000, p. 44). O primeiro se refere aos elementos que compõem a totalidade de uma obra/texto e também invadem todos os traços da mesma. Já o pathos permite ao espectador/leitor sair de si, de sua condição ordinária, como num sonho. Tanto Lisa quanto Maria, durante seus tratamentos, contaram sonhos, que vamos privilegiar neste texto, por retratarem o que Freud denominou o lugar do inconsciente, "uma outra cena" (Costa, 2006, p. 58), como num filme. Além disso, "Numa análise não intervimos unicamente na medida em que interpretamos o sonho do sujeito - se é que interpretamos — mas como já estamos, a título de analista, na vida do sujeito, já estamos em seu sonho" (Lacan, 1995, p. 194). 


\section{Os Relatos dos Sonhos}

\section{O Sonho de Lisa:}

- Não sei se foi um sonho ou se realmente aconteceu. Havia uma psicóloga que disse que a dúvida que eu tinha sobre quem era meu pai, não era uma dúvida importante. Fui ao consultório desta psicóloga. Entrei junto com uma rajada de vento e todos os documentos dela, que estavam sobre sua escrivaninha, voaram e se espalharam pelo chão.

\section{O Sonho de Maria:}

— Eu vinha de ônibus que passava pelo riacho do C V. Uma guria do ônibus disse:

— quem desce aqui, vocês sabem o que acontece...

Maria completou: Rodam, a vida para, são estupradas!

\section{Análise do Sonhos}

\section{Análise do sonho de Lisa}

No relato de Lisa aparece o indício da abolição da "prova de realidade" na dúvida: é sonho ou realidade? A prova de realidade é a prática de distinguir as percepções das ideias. Meynert (citado por Allouch, 2004, p. 89) para apoiar sua aproximação entre o sonho e a amentia, diz que há uma abolição da diferença entre sonho e estado de vigília na amentia. aí ocorre "um defeito de associação". Tal indício da abolição da prova de realidade também apareceu em uma sessão em que Lisa ouviu (alucinou) a voz do terapeuta da oficina de música, que não se encontrava presente no local. No relato do sonho, Lisa apresenta o fato que desencadeia toda a sua angústia: quem é seu pai, I ou B.? Esta dúvida surge em praticamente todas as sessões e é a causa da sua falta de vontade, segundo ela. A dúvida surgiu aos dezenove anos, quando começou a andar sempre com a mesma roupa, embora tivesse outras para usar, emagreceu muito e começou a se trancar no quarto. Foi internada em uma clínica. Ao perguntar ao médico da internação como o pai havia reagido ao saber que ela estava internada, ouviu a resposta: - Ele ficou indiferente. A dúvida de Lisa quanto ao estatuto de sonho ou realidade se desdobra na dúvida sobre sua paternidade, o fato mais importante da sua vida e que constituiu uma ausência de inscrição primordial. Esta ausência prejudicou sua capacidade de articular as palavras imprimindo uma fala entrecortada e difícil que se complementa com desenhos apresentados ao longo das sessões. Nestes desenhos repete-se uma paisagem com montanhas ao fundo e sóis (três) entre as montanhas. No primeiro plano aparece uma árvore à beira do abismo e a figura de um furacão que vem da terra em direção ao sol. Há um olho na árvore. Ao falar no desenho, Lisa diz que ela é a árvore e sua intuição, o olho. A árvore é ajudada pelo sol. Sua mãe é o furacão. O abismo representa a morte que sente iminente, mas não tem medo, pois há a esperança de outras vidas, indicadas pelas montanhas no horizonte. O furacão do desenho aparece também, no sonho, como lufada de vento que espalhou os papéis pelo chão. Há a referência à queda no abismo, à queda dos papéis e dela mesma que se joga em algum momento de sua vida, da janela de um edifício. Todo sonho é transferencial e assim pode apresentar a ideia do que será o percurso da análise. Neste sonho de Lisa, a ideia dos documentos da psicóloga que caem e se espalham pelo chão poderia ser "premonitório" do fim a análise. Um fim em que há uma queda, provocada por uma lufada de vento (ela falou com a mãe) e um cair fora (desistiu). Também, ao entrar no consultório junto com a lufada de vento, há certo desafio, na medida em que a psicóloga contraria a percepção de Lisa, sobre a importância da dúvida quanto à filiação. Lisa se posiciona ao lado da lufada de vento, a família, e desafia a psicóloga. Este desafio aparece quando diz, literalmente, que estava desafiando a terapeuta, se mantendo muda durante várias sessões. Desconfiava que estivessem levando informações dela para a outra instituição, ou mesmo que as sessões poderiam estar sendo gravadas. O desafio resultaria da desconfiança provocada pela dúvida sobre sua filiação.

Freud (1917/1999) distingue as ideias, das representações de coisas. Fala do sonho ou alucinação como um processo em que as representações de palavras regridem às representações de coisa, representações plásticas. Nele existe livre comunicação entre catexias de palavras (Pcs) e catexias de coisas (Ics), na esquizofrenia, não. Nesta última ocorre tentativa 
de restituição, restauração de uma catexia libidinal às ideias de objeto, não há regressão tópica. O que se torna objeto de modificação do processo primário são as palavras nas quais o pensamento pré-consciente foi expresso. As palavras são condensadas e transferem catexias umas às outras, podendo chegar a uma única palavra e haveria na fala uma predominância "do que tem a ver com as palavras sobre o que tem a ver com as coisas" (D'Agord, 2005, p. 5). A regressão tópica, ausente na esquizofrenia, decorre do recalque/censura que impede uma formulação verbal clara do desejo e encontra na densidade da imagem, no sonho, uma expressão alusiva.

Lisa apresenta um sonho/alucinação em que os fatos mais importantes de sua análise estão expostos claramente, não necessitando, aparentemente, de interpretação: A dúvida sobre sua filiação, a importância desta dúvida na sua vida, o tratamento, a queda. Por outro lado, os desenhos apresentados constituem uma tentativa de produzir uma cena pictórica, como um sonho, uma tentativa de restauração (ou instauração?) de uma catexia libidinal as ideias de objeto.

Entretanto, estudando mais atentamente A Interpretação dos Sonhos de Freud (1900-01/1996, pp. 521-523) lemos no trecho sobre a Elaboração Secundária o comentário de que nem tudo o que está presente num sonho decorre de pensamentos oníricos. Existem intercalações e acréscimos pela instância censora que servem de elo, entre dois fragmentos de conteúdo onírico, preenchendo lacunas. São os pensamentos agregadores, os que primeiro esquecemos e cuja finalidade é de preencher lacunas da estrutura do sonho, para que este perca sua aparência de absurdo e incoerência e afigure-se lógico.

"Se um sonho diurno já tiver sido formado na trama dos pensamentos oníricos, este quarto fator do trabalho do sonho [pensamentos agregadores] preferirá apossar-se do sonho diurno já pronto e procurará introduzi-lo no conteúdo do sonho" (Freud, (1900-01/1996, p. 525).

É muito frequente a fantasia já pronta formar um fragmento do sonho, constituído por outros fragmentos e amalgamados por uma matriz de pensamentos agregadores.

Propomos então que o sonho de Lisa seja composto de fragmentos oníricos cimentados por elementos agregadores usados na Elaboração Secundária-

\section{Análise do Sonho de Maria}

Este é também muito claro, e expressa o desenvolvimento do seu tratamento. As ideias presentes aparentemente não sofreram elaboração para serem decifradas. A ida de ônibus ao local CV e o fato do ônibus ter sofrido pane, evitou que ela fosse ao local onde se armava um complô para esquartejá-la, segundo seu relato em sessão. Esta perseguição ocorrida no ano anterior ao tratamento tinha produzido sequelas em Maria. Ela sofria de paradas. Vinha pela rua, e de repente, parava de caminhar, parava de pensar, parava de falar. Seus estudos sofriam também com o seu estado psíquico. Tinha dificuldade de estudar. Era resistente à prescrição da medicação pelo psiquiatra e somente o desejo de aprovação nas matérias a impedia de controlar sua mente sem as medicações.

Entretanto, numa leitura mais atenta à "Interpretação dos Sonhos", Freud (1900-01/1996) afirma que o trabalho dos sonhos não pode criar "ditos".

Por mais que figurem nos sonhos ditos e conversas, sejam eles racionais ou irracionais, a análise invariavelmente prova que o que o sonho fez foi extrair dos pensamentos oníricos fragmentos de ditos realmente pronunciados ou ouvidos [...] assim os ditos nos sonhos tem uma estrutura similar a da brecha, na qual blocos razoavelmente grandes de vários tipos de rocha são consolidados por uma massa intermediária de ligação. (Freud, (1900-01/1996 pp. 451-452)

Temos, no sonho de Maria, um "dito" proferido pela guria do ônibus, da qualidade sensorial da fala, descrito pela sonhadora, e que vê o que se passa, como o que acontece com a câmera filmadora.

— quem desce aqui, vocês sabem o que acontece...

\section{Interpretações dos Sonhos}

Ambos os sonhos, como inicialmente apontamos, aparentam realizar desejos, temas iniciados e interrompidos como o tratamento psicológico de Lisa e a viagem de Maria. Mas, se Maria esteve sempre usando uma linguagem do inconsciente nas sessões e Lisa não sabia se relatara um sonho ou um acontecimento real, eis uma dúvida, os desejos satisfeitos nestes sonhos são conscientes ou inconscientes? Estes sonhos são de desejo? 
O sonho de Maria, assim como o de Lisa apresentam, a estrutura de "Brecha" na qual blocos razoavelmente grandes de vários tipos de rocha, fragmentos, são consolidados por uma massa intermediária de ligação (elementos agregadores).

O "dito" do sonho de Maria tem um conteúdo que pode ter sido arrancado de seu contexto, cortado aos pedaços.

"Eu vinha de ônibus que passava pelo riacho do C V. Uma guria do ônibus disse:

- quem desce aqui, vocês sabem o que acontece...

Eu disse: rodam, a vida para, são estupradas!"

Quando Freud (1900-01/1996, p. 419) fala nos sonhos típicos, cita aqueles sobre a perda de um trem e dos sonhos com exames, por causa da similaridade de seu afeto.

São sonhos de consolação para o medo de morrer sentido no sono; o sentimento de angústia está ligado à expressão de consolo. Partir numa viagem seria um símbolo da morte e a perda do trem seria uma espécie de consolo "Não se preocupe, você não morrerá" ou "Não tenha medo, nenhum mal lhe acontecerá desta vez, tampouco".

Maria vinha no ônibus, já havia partido, e o medo era de que a vida parasse. A morte aparece neste sonho associada a parar no tempo e a rodar nos exames. Foi a parada no tempo do estupro que a fez trazer na primeira sessão aquele sofrimento inicial. Uma viagem interrompeu, por seis semanas a análise, quando Maria viajou para "algum lugar na América do Sul" onde foi fazer trabalho voluntário associado a seu curso de formação profissional. O medo da morte, comumente se associa às viagens aéreas, pode se relacionar ao medo que o avião caia. Também foi uma viagem que provocou um surto em que Maria tentando impedir a viagem da irmã, lhe rasgou o passaporte. As viagens ao Norte do país, para visitar o pai, são relembradas nas sessões.

— Quem desce aqui, pode ser um "dito" ouvido na viagem, por exemplo, em conexões aéreas, frequentemente se ouve Quem desce aqui....

Aqui, que lugar é este? Perguntamo-nos. Que realidade psíquica é esta em que a vida para? Estaria ela se referindo à sua futura internação, em função do diagnóstico de esquizofrenia?

- Vocês sabem o que acontece....

A questão do saber perpassa a fala de Maria em todas as sessões. As aulas na faculdade podem ter contribuído com este “dito”, ouvido dos professores: — vocês sabem o que acontece...

Maria questiona-se sobre a sua capacidade cognitiva, diz ter um bloqueio, não pensar, ser burra. O próprio riacho onde o ônibus passa e para é próximo a uma instituição de ensino.

A sonhadora explica, no sonho, o que acontece:

Rodam... Maria havia rodado (reprovado) na disciplina que era requisito para fazer seu estágio profissional. Mesmo assim, entrou com o pedido para fazer o estágio e a angustiava a resposta negativa que poderia ter.

A vida para... Ela passava longos períodos só, em casa. Sentia-se presa dentro de si mesma; sempre fora tratada como se não existisse.

São estupradas... Este fato aparece na origem, segundo Maria, aos dois anos e meio, e repete-se durante o tratamento, quando ela diz que um vizinho a estuprou e depois, acusa outro colega. Finalmente confessa que tem o "fetiche" de ser estuprada por vários homens.

O “fetiche”, segundo Freud (1927/2006b, p. 162) “...não é o substituto de um pênis qualquer, mas sim de um determinado pênis, todo especial... é o substituto do falo da mulher (da mãe)...”. Ser objeto sexual de vários homens, como fetiche implica uma radical exclusão da posição de sujeito e mais do que ser gozado como objeto, se trata do abjeto.

A abordagem lacaniana da esquizofrenia parte do modelo da neurose como parâmetro, mas posteriormente demarca dois pontos distintos, salientados como estruturais: a ausência do ponto de basta (point de capiton) "um núcleo da subjetividade organizado em torno de uma falta, a castração", e a foraclusão. A ausência do ponto de amarração entre significante e significado explicaria a predominância da palavra sobre a coisa (D'Agord, 2005, p. 5). A foraclusão seria a rejeição do ponto de basta, desta amarração central em torno de uma falta. $\mathrm{O}$ desencadeamento da crise ocorre quando o significante do ponto de basta que foi rejeitado retorna, no real, por não ter sido simbolizado pelo sujeito. A este retorno do significante, no real, que segue o modelo do retorno do recalcado no simbólico para as neuroses, Calligaris (1989, p. 39) chama de "metáfora delirante", convocando a constituição de uma "sexuação, homem ou mulher, no real". Tal metáfora poderia se associar ao "fetiche" de Maria.

Quanto ao sonho de Lisa, supomos ser composto por fragmentos de devaneios diurnos.

- Entrei junto com uma rajada de vento e todos os documentos dela, que estavam sobre sua escrivaninha, voaram e se espalharam pelo chão. 
Neste devaneio, os documentos espalhados pelo chão podem ser associados à dúvida quanto à filiação. I havia assinado alguns documentos de identidade dela; B não se preocupava, não perguntava sobre sua vida. Também ouvira o irmão mais velho falar a um advogado: - Eu sou o filho legítimo. Lisa ouviu ou alucinou esta fala como uma atribuição desubjetivante de que, portanto, ela não era filha legítima, sendo a legitimidade comprovável com documentos.

Mas os documentos eram da psicóloga, e o espalhamento dos documentos pelo vento implica perda da identidade, onde o elemento ativo é o vento (a mãe) que entra junto com Lisa. Esta perda da identidade, do eu, que, segundo Freud é a soma das identificações do sujeito, aponta para uma separação das identificações, que aparece na fala da primeira sessão. Seria um fenômeno que evoca a imisção do sujeito, nomeada por Lacan (1995, p. 204) no aparecimento das identificações freudianas que entram e se intrometem no exame médico de Irma: Otto, Leopold e Professor M. (Meynert?) quando ele, Freud, cai fora do "Sonho da Injeção de Irma".

Finalizamos a interpretação destes dois sonhos com algumas interrogações. Há realização de desejo nestes sonhos? Em Além do princípio do prazer, Freud (1920/2006c) diz que na repetição de um sonho traumático, a função de sonhar está perturbada, não se trata de desejo, mas de compulsão à repetição. Há algo desta ordem nos sonhos em questão?

\section{Peculiaridades da Transferência e do Fim do Tratamento}

Voltemos ao caso Dora (Freud, 1901/1989), retomado por Lacan (1998a, p. 224) que descreve a experiência psicanalítica se desenrolando na relação de sujeito a sujeito, utilizando só palavras e onde a verdade se transmuta em inversões dialéticas. Dora identificou-se com Freud e com o Sr K, revivendo a relação com o irmão, transferência revelada pelo tratamento psicanalítico, na interpretação de Lacan (1998a). Entretanto, Freud interpretou aí, um interesse amoroso entre Dora e o Sr. K. (e com ele mesmo, Freud) o que mais tarde revela ter sido um "erro técnico".

Freud provocou uma supressão do processo dialético da análise pelo aparecimento dos modos permanentes pelos quais o sujeito constitui seus objetos, ou seja, ao se recusar a ser objeto amoroso de sua paciente, opôs uma resistência. A transferência pode ser vista como um corte na cadeia associativa do analisante e se justapor à resistência, quando o paciente cessa de associar e emerge a presença do analista.

Voltando a Lisa, e a sua saída do tratamento, apontamos uma possível resistência se justapondo à transferência. Ela havia comentado sua bissexualidade em sessão e dizia temer que uma mulher casada se apaixonasse por ela. Também perguntou à analista se esta gostava de tomar chá, e que havia tomado chá com uma mulher por 45 minutos. A resposta, de que não gostava de tomar chá, por parte da analista, pode ter desencadeado uma resistência.

A transferência é permeável à ação da fala e sustentáculo da ação da fala (Lacan, 1992, p. 175). Embora feita do mesmo estofo do amor, é um artifício, uma vez que se refere inconscientemente a um objeto que reflete outro (Roudinesco \& Plon, 1998, p. 769), uma metáfora, encenação da realidade do inconsciente.

É na transferência que se estabelece o diagnóstico na clínica psicanalítica que é estrutural. Se na neurose o sujeito aposta que haja ao menos um que saiba lidar com a Demanda imaginária do Outro, na psicose é o próprio sujeito que deve se proteger da Demanda imaginária do Outro. Allouch $(2005$, p. 446) escreve que na transferência psicótica alguém fala a alguém "o que o Outro lhe faz saber". Calligaris (1989) também discute a transferência na estrutura psicótica. Aquém da crise, o analista é interpelado como um saber sem agente, sem sujeito suposto, é uma consulta à psicanálise que pode acabar numa crise se o analista o recebe como um pedido terapêutico, porque vai produzir uma injunção que é uma ordem irrevogável.

Maria em mais de uma sessão interpelou a psicanálise sobre o que é o ciúme e também o sobre o que é a amizade. Visava o seu próprio percurso no laço com a mãe e com os colegas, querendo um saber total que a permitisse fazer amigos.

Como consequência da injunção, ainda segundo Calligaris (1989), sempre há ao menos uma alucinação auditiva que manifesta outra posição transferencial possível: o lugar da instância paterna que volta no real. Falar deste lugar implica ser escutado pelo paciente como uma alucinação auditiva. Neste caso, o abandono a que Maria se referiu na última sessão, poderia estar reatualizando algo que já havia acontecido, pois tudo o que acontecia, já estava previamente definido, segundo ela.

O estado crepuscular é o momento em que o saber do sujeito não vale mais, fica sem nenhum tipo de significação. Neste estado, o delírio, ainda não se constituiu, situação que vai organizar uma transferência em relação à posição imaginária de um Outro devorador. O delírio é a tentativa de construir uma metáfora paterna, uma filiação, uma defesa e sua significação, no real.

Para Lisa, a filiação se dá partir da reencarnação de sua tia. Ela diz ser o espírito da tia em um corpo, eliminando a contribuição do pai.

Para Maria, o relato de os colegas entrarem no seu computador, e-mail e televisão para roubar seus dados pessoais, e tocarem músicas em frente a sua casa, seria uma tentativa de separar o dentro e o fora, o eu e o outro com "um instrumento construído pelo delírio" (Tausk, citado por Righini \& Neto, 2008, p. 95). O seu "fetiche" seria também uma defesa (delírio). 
Apontamos o fator desencadeador da crise de Lisa, a injunção, o ter de assumir um posto de professora, e Maria, a aproximação do estágio profissional, posições que as colocariam no registro do Simbólico. A alucinação auditiva de Lisa apareceu como voz, e no caso de Maria, músicas a acordavam durante a noite, diziam o quanto ela incomodava o vizinho, e também a ameaçavam de morte.

\section{Considerações Finais}

Se retomarmos os elementos composicionais, os fragmentos que estas duas pacientes escolheram para ilustrar suas falas ao longo de suas análises, podemos identificar traços fundamentais como a organicidade das narrativas caracterizada por elementos que nutrem suas histórias como um todo e invadem todos os traços das suas falas até o término dos tratamentos. A outra característica destas narrativas, usando os critérios de composição de obra fílmica é o pathos, que nestas composições, parece ser o encontro com a alucinação e com os sonhos, que Freud (1900-01/1996) chama de via régia para o inconsciente.

O sonho resulta de um trabalho em que os pensamentos inconscientes são transformados em imagens segundo um processo psíquico primário, devido à censura. A partir narrativa do sonho, a interpretação feita pelo analista aponta a uma realização de desejo. O processo psíquico primário foi também identificado por Freud (1915/2006a, p. 48) nas "formações substitutivas esquizofrênicas". Nestas, as palavras são submetidas à condensação e deslocamento e o processo pode chegar a uma única palavra que representa uma cadeia de pensamentos. É na linguagem "floreada", destes pacientes, na qual palavra e coisa não se equivalem que Freud percebe a diferença da fala em relação aos pacientes neuróticos. Ele parte da neurose mas aponta diferenciações na psicose.

No nosso texto trabalhamos com sonhos de pacientes diagnosticadas como esquizofrênicas, em que as narrações das imagens oníricas não se diferenciam tanto das descrições de cenas de vigília que supostamente não estão destinados a realizar desejos. Obedecem à compulsão à repetição de fatos traumáticos nos conduzindo ao real, componente do ternário (simbólico, imaginário e real) que Lacan introduz no campo freudiano permitindo ver as questões psicanalíticas de outra maneira, qual seja, o inconsciente tem a estrutura de uma linguagem. É na linguagem, na fala das pacientes deste estudo ao contar seus sonhos, em transferência, que identificamos suas estruturas subjetivas, suas subjetividades.

Na nossa construção há uma repetição que não cessa de se escrever, independentemente da nossa vontade, desde o título inicialmente escolhido em alusão a "Fragmento da Análise de um caso de Histeria", apresentado a partir da análise de dois sonhos, passando pelos fragmentos da fala das pacientes e finalmente a estrutura fragmentaria dos sonhos, descoberta, $a$ posteriori, pela análise. A compulsão à repetição é associada por Freud (1920/2006c) em "Além do Princípio do prazer”, aos sonhos traumáticos diferenciando estes dos sonhos de realização de desejo.

\section{Referências}

Agamben, G. (2007). Profanações. São Paulo: Boitempo.

Allouch, J. (2004). Erótica do luto: No tempo da morte seca. Rio de Janeiro: Companhia de Freud.

Allouch, J. (2005). Paranóia Marguerite ou A Aimée de Lacan. Rio de Janeiro: Companhia de Freud.

Calligaris, C. (1989). Introdução a uma clínica diferencial das psicoses. Porto Alegre: Artes Médicas.

Costa, A. M. M. (2006). Sonhos. Rio de Janeiro: Zahar.

D’Agord, M. (2005). Esquizofrenia, os limites de um conceito. (Link)

Freud, S. (1989). Fragmento da análise de um caso de histeria. In J. Strachey (Ed.), Edição Standard Brasileira das Obras Psicológicas Completas de Sigmund Freud (Vol. 7, pp.12-115). Rio de Janeiro: Imago. (Originalmente publicado em 1905 [1901])

Freud, S. (1996). A interpretação dos sonhos (segunda parte) sobre o sonho. In J Strachey (Ed.), Edição Standard Brasileira das Obras Psicológicas Completas de Sigmund Freud (Vol. 5., pp. 371-777) Rio de Janeiro: Imago. (Originalmente publicado em 1900-1901) 
Freud, S. (1999). Suplemento metapsicológico a teoria dos sonhos. In S. Freud, Artigos sobre Metapsicologia. Rio de Janeiro: Imago. (Originalmente publicado em 1917)

Freud, S. (2006a). O inconsciente. In L.A. Hanns (Coord.), Escritos sobre a psicologia do inconsciente (Vol. II: 1915-1920, pp. 13-74). Rio de Janeiro: Imago. (Originalmente publicado em 1915)

Freud, S. (2006b). Fetichismo. In L.A. Hanns (Coord.), Escritos sobre a psicologia do inconsciente (Vol. III: 1923-1938, pp. 159-170). Rio de Janeiro: Imago. (Originalmente publicado em 1927)

Freud, S. (2006c). Além do princípio do prazer. In L.A. Hanns (Coord.), Escritos sobre a psicologia do inconsciente (Vol. II: 1915-1920, pp. 123-198). Rio de Janeiro: Imago. (Originalmente publicado em 1920)

Froemming, L. (2000). Era como num sonho era como num filme. Revista da Associação Psicanalítica de Porto Alegre, 18, 37-54.

Gagnebin, J. M. (2007). História e narração em Walter Benjamin. São Paulo: Perspectiva.

Gagnebin, J. M. (2009). Lembrar escrever esquecer. São Paulo: Ed. 34.

Goldim, J. R., \& Fleck, M. P. (2010). Ética e publicação de relatos de caso individuais. Revista Brasileira de Psiquiatria, 32(1), 2-3. (Link)

Hanns, L. (1996). Dicionário Comentado do Alemão de Freud. Rio de Janeiro: Imago.

Lacan, J. (1992). O Seminário, Livro 8: A transferência. Rio de Janeiro: Zahar.

Lacan, J. (1995). O Seminário, Livro 2. O eu na teoria da Freud e na técnica da psicanálise. Rio de Janeiro: Zahar.

Lacan, J. (1998a). Intervenção sobre a transferência. In J. Lacan, Escritos (pp.214-225) Rio de Janeiro: Zahar.

Lacan, J. (1998b). Para além do princípio de realidade. In J. Lacan, Escritos (pp.77-95) Rio de Janeiro: Zahar.

Lafayette M. M. (2013). A Princesa de Clèves. Lisboa: Leya. (Link)

Righini, R. D., \& França Neto, O. (2008). O aparelho de influenciar da psicose: o artifício de Vitor Tausk. Mental, 6(11). (Link)

Roudinesco, E., \& Plon, M. (1998). Dicionário de Psicanálise. Rio de Janeiro: Zahar.

\section{Endereço para correspondência}

Marisa Terezinha Garcia de Oliveira

End.: Rua Campos Elíseos 251, Glória, Porto Alegre, RS. CEP: 90870-020

Email:mtgoliv@gmail.com

Liliane Seide Froemming

End.: Rua Silveiro, 1114, apt. 301, Santa Tereza. Porto Alegre, RS. CEP: 90850-000

Email: lilifrom@portoweb.com.br 